\title{
A case of neuralgic amyotrophy with contralateral recurrence
}

\author{
Kimberly L Aderhold, Lisa H Carpenter, Krysta L Brown, Ronald K Herb \\ The Reading Hospital and Medical Center, Pennsylvania, USA
}

Received: February 13, 2016

DOI: $10.5430 /$ crim.v3n $4 p 50$
Accepted: March 22, 2016

Online Published: September 29, 2016

URL: http://dx.doi.org/10.5430/crim.v3n4p50

\begin{abstract}
Neuralgic amyotrophy is a brachial plexopathy of uncertain etiology which presents as acute neuropathic pain with subsequent weakness and sensory changes. It is believed that this disease process is under recognized in the primary care setting. We present a case of a 58-year-old male who presented to the outpatient clinic with severe pain and new onset weakness in his left arm. The same patient presented several months later with the same presentation in his right arm. By the end of the case report, readers should be able to recognize the common symptoms of neuralgic amyotrophy, as highlighted by this patient's presentation.
\end{abstract}

Key Words: Neuralgic amyotrophy, Neuropathic pain, Parsonage-turner syndrome

\section{INTRODUCTION}

Neuralgic amyotrophy is an under-recognized brachial plexopathy of uncertain etiology. Also known as ParsonageTurner Syndrome or brachial neuritis, this disease process has a typical presentation of acute onset of neuropathic pain that is worse at night followed by weakness and sensory changes in the upper extremity. ${ }^{[1,2]}$ The minimal incidence is thought to be 2-3 cases per 100,000 persons, however the true incidence is postulated to be $20-30$ cases per $100,000 .^{[1,3]}$ The difference between minimal and true incidence is presumed to be due to under-recognition of the disease process. ${ }^{[3]}$ Timely treatment is vital for optimizing patient improvement, and so it is important for the primary care physician to quickly recognize the typical pattern of neuralgic amyotrophy in order to improve recovery. To help illustrate this point, we report a case of idiopathic neuralgic amyotrophy that subsequently reoccurred in the contralateral limb.

\section{CASE PRESEntation}

A 58-year-old male presented to an outpatient clinic with a complaint of "knife-like" pain in his neck and weakness of his left arm. He also reported numbness of the posterior aspect of the forearm, the first and second fingertips, as well as the lateral aspect the first finger. The patient reported these symptoms were similar to ones he had experienced when he suffered from a right sided C6 radiculopathy several years earlier. On examination, the clinician noted decreased range of motion of his left shoulder and decreased strength of the biceps. Additionally, his exam revealed decreased sensation of light touch on his left arm and first through third fingers in the C7-C6 distribution. The patient did not recall any preceding injury to his left side, although he did recall having had pneumonia several months earlier.

Given his history of similar symptoms related to his previous C6 radiculopathy, a cervical spine $\mathrm{x}$-ray was ordered. This imaging noted overall degenerative changes with moderate

\footnotetext{
*Correspondence: Lisa H Carpenter; Email: lisa.carpenter@readinghealth.org; Address: The Reading Hospital and Medical Center, Pennsylvania,
} USA. 
disc space narrowing at C6-C7 with anterior and posterior degenerative spurring. A cervical spine MRI was also performed and noted mild degenerative disc bulges from $\mathrm{C} 3$ to C7 without significant cord compression or neural impingement.

Electromyography (EMG) and nerve conduction studies revealed that the biceps branch and sensory branch of his left musculocutaneous nerve were severely impaired; however, the brachialis branch was completely spared. Nerve conduction study also demonstrated impairment of the long thoracic, pectoral, and median nerves. Fibrillations were present in the left biceps brachii but not the brachialis. All muscles innervated by the median nerve displayed fibrillations, including the pronator teres, flexor carpi radialis, flexor pollicis longus and opponens pollicis. Due to the non-radicular pattern of denervation, the diagnosis of neuralgic amyotrophy was suggested. The patient was subsequently sent to physical therapy and actively participated in home exercises. His Neck Disability Index Score improved from 34/100 to $12 / 100$ and his QuickDASH score improved from 38.63/100 to 29.54/100.

He was prescribed corticosteroids, opioids, and NSAIDs, which initially resolved his pain. Unfortunately, his pain returned after the first course of steroids and a second course was required. His pain resolved after this second course but the weakness persisted. At follow up one month later, he still had significant left bicep muscle weakness and numbness in the aforementioned distribution. However at that time, he also had developed marked atrophy of the left biceps muscle and adductor pollicis muscles (see Figures 1,2).

The patient declined further evaluation by Neurology and continued his physical therapy exercises at home. He ultimately had complete resolution of his left sided weakness, but with persistent numbness over the lateral forearm and thenar eminence.

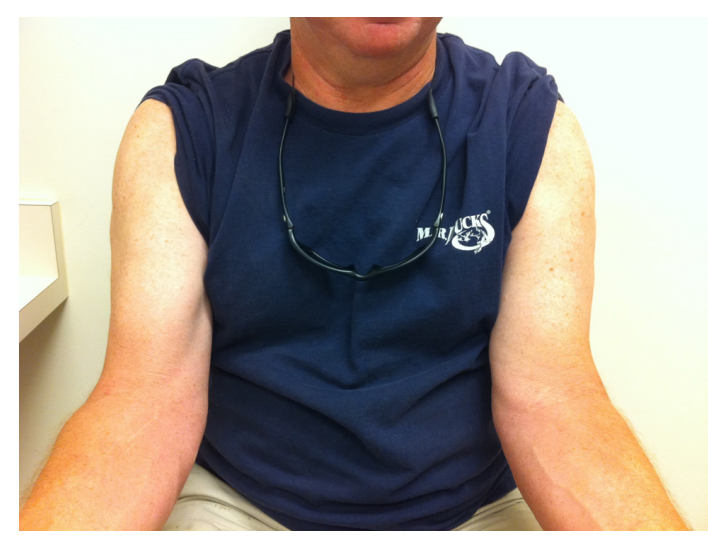

Figure 1. Atrophy of the left bicep muscle during the first episode of neuralgic amyotrophy

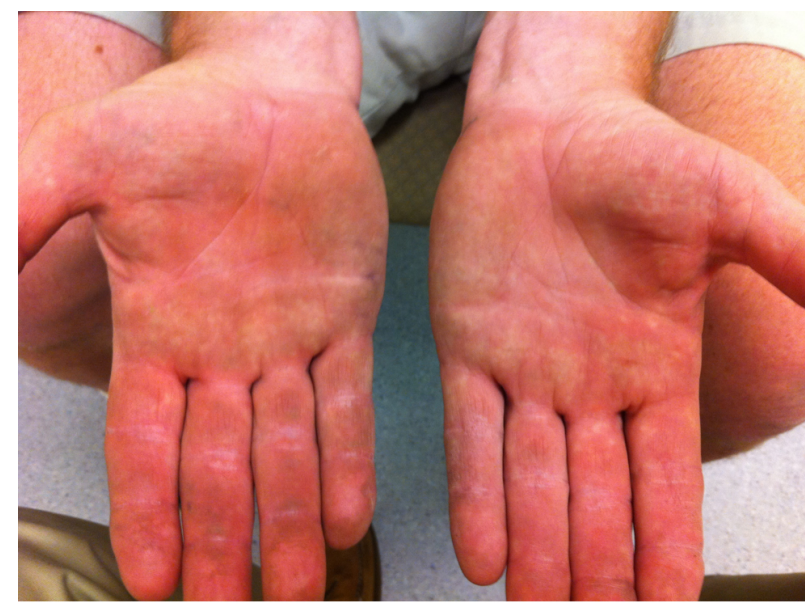

Figure 2. Adductor pollicis muscle atrophy of the left hand during the first episode of neuralgic amyotrophy

Fifteen months later, he presented to the office with the same "knife-like" pain in his neck, which now radiated down his right shoulder. Again he had associated numbness extending laterally down to his right hand with weakness in flexion of the right arm and extension of his wrist. Two weeks prior to this episode, he reported a nonspecific flu-like illness.

On examination, he had decreased sensation over the lateral aspect of his right arm. There was marked weakness in the patient's adductor pollicis, triceps, and wrist extensor muscles which resulted in a prominent wrist drop. Given his prior episode of neuralgic amyotrophy he was immediately started on corticosteroids and sent for electrodiagnostic and nerve conduction studies. Within one week his pain had improved but the numbness and muscle weakness remained. At this point he was continued on prednisone and sent for neurology and physiatry consultation.

Repeat EMG and nerve conduction studies revealed severe high right radial nerve lesion with fibrillations. He also had a partial median nerve lesion involving the pronator teres with decreased recruitment but no fibrillations. MRI without contrast of the brachial plexus showed normal appearance of the right brachial plexus. The lower cervical nerve roots were intact and normal in course and caliber without STIR or T1 signal abnormality. There was no T1/STIR hyperintense mass or fluid collection along the course of the brachial plexus. Due to involvement of both median nerve and radial nerve on EMG, without evidence of involvement of cervical nerve root or brachial plexus on MRI the diagnosis of idiopathic neuralgic amyotrophy was made. Patient was treated with prednisone, initially $40 \mathrm{mg}$ for 30 days, followed by $20 \mathrm{mg}$ for 30 days followed by a 6-week prednisone taper. He was also treated with physical therapy.

At follow up, his pain had resolved with prednisone. He 
demonstrated improved muscle strength in his right triceps muscle and hand grip, as well as improved range of motion in right forearm internal and external rotation. Shoulder abduction improved to about 100 degrees. Unfortunately, he continues to experience persistent wrist drop (see Figure 3) and decreased sensation to sharp touch over the C6 dermatome, although light touch and temperature sensation are intact.

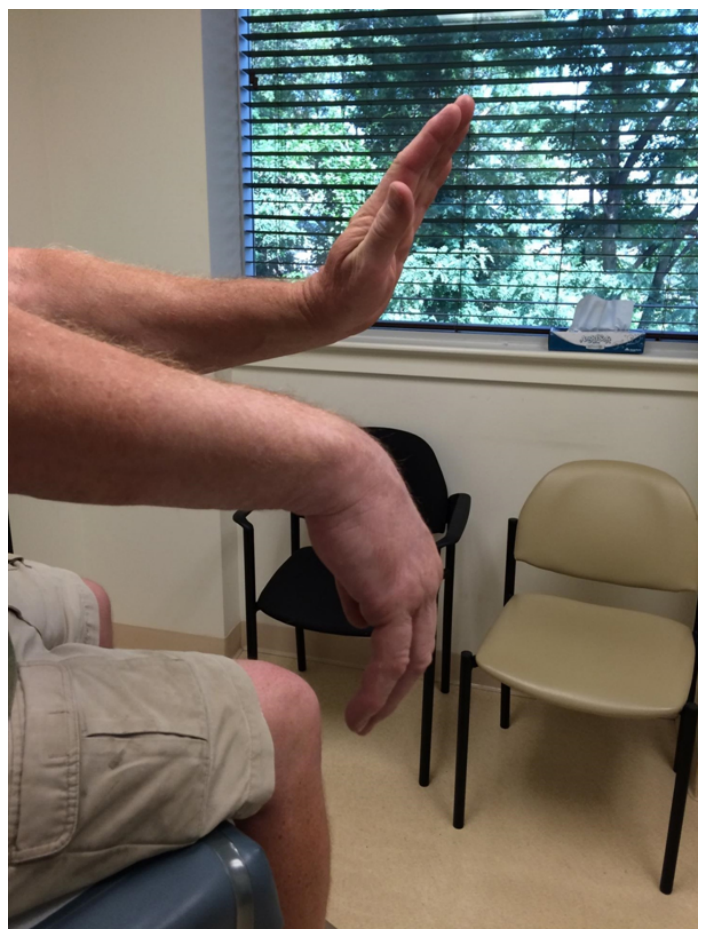

Figure 3. Prominent wrist drop of the right hand during second episode of neuralgic amyotrophy

\section{Discussion}

Neuralgic amyotrophy most commonly follows a typical progression that begins with severe neuropathic pain. Pain is often present for hours to weeks and then gradually subsides giving way to weakness. Weakness can occur at the same time as pain, but does not proceed it. Muscle atrophy is then observed approximately 2-4 weeks following the onset of weakness. Finally, sensory changes can occur but are typically more mild than the motor and pain manifestations. ${ }^{[4]}$ The pathophysiology behind this disease is not well understood, but has been associated with preceding surgical procedures, infections, and immunizations. ${ }^{[3,5,6]}$ Although NA has a "classic" presentation involving distribution in the brachial plexus involvement of other peripheral nerves including the lumbosacral plexus and lower cranial, phrenic, and scapulothoraic nerves have been reported. ${ }^{[1,3,7,8]} \mathrm{A}$ "winged scapula" may be found in up to two thirds of patients if the long thoracic nerve is involved. ${ }^{[7,9]}$ It usually presents uni- laterally but can occur bilaterally in up to $28.5 \%$ of patients according to one study which analyzed the characteristics of 246 cases of NA. ${ }^{[3]}$ Dysesthesia, numbness, and hypoesthesia are within the array of symptoms and were reported in nearly three quarters of patients in one report. ${ }^{[3,7]}$ Nevertheless, there have even been reports of painless attacks that present with weakness as the primary symptom. ${ }^{[7]}$

Here we present a case of idiopathic neuralgic amyotrophy, however a hereditary form of neuralgic amyotrophy does exist. The presentation parallels that of the idiopathic variety, however occurrence is typically at a younger age and unfortunately recurrence is more common. ${ }^{[3]}$ While some genetic heritability exist, ${ }^{[10]}$ the SEPT9 gene, initially identified in 1996 , is the only gene that is known to cause hereditary neuralgic amyotrophy. ${ }^{[11]}$ This gene is inherited in an autosomal dominant fashion. ${ }^{[12]}$

In addition to the broad spectrum of possible presentations, NA may represent a challenge to the primary care physician because it must be distinguished from other diseases that present with analogous symptoms. There is a long list of differential diagnoses for idiopathic neuralgic amyotrophy including cervical radiculopathies caused by nerve impingement due to cervical spine or disk degeneration, rotator cuff tears, shoulder impingement syndrome, adhesive capsulitis, Pancoast tumor, trauma, iatrogenic damage from irradiation and surgery. ${ }^{[3,9]}$ A thorough physical examination and history will often help the astute clinician to rule out several possible etiologies promptly. Imaging, including cervical spine x-ray, cervical MRI, and brachial plexus MRI further distinguish the diagnosis. Imaging, including cervical spine X-ray, cervical MRI, and brachial plexus MRI further distinguish the diagnosis. While MRI findings can vary depending on the acuity of the condition when the MRI is preformed, several specific MRI findings have been identified in patients with NA. Muscle denervation can be seen which is manifested as an increase in T2 weighted signal which coincides with edema. This edema can persist and atrophy of affected muscles may then be seen on MRI. ${ }^{[13]}$ However, the brachial plexus imaging is usually unremarkable in NA. ${ }^{[3,14]}$ EMG testing and nerve conduction studies (NCS) are especially useful in diagnosis of NA. As was demonstrated in our patient, NCS and EMG were able to reveal reductions in somatosensory evoked sensory nerve action potentials in multiple places along the brachial plexus. ${ }^{[1,3]}$ Despite a thorough exam and extensive work up, NA is still a diagnosis of exclusion with no clearly defined role for EMG, NCS, or imaging.

Unfortunately, idiopathic NA has a fairly high rate of recurrence. In one case series, $26 \%$ of patients suffered recurrence 
in a 6-year follow-up. The lifetime risk of recurrence could therefore be quite high. As many as $12 \%$ of patients have been documented to experience recurrence within one year. The relatively high risk of recurrence insinuates there is likely some underlying peripheral nerve pathophysiology that renders those with idiopathic NA more susceptible to auto-immune insults. ${ }^{[3]}$

Standard treatment for NA is prompt initiation of corticosteroids or immune modulators along with physical therapy. A recent Cochrane review found that high quality evidence for the use of steroids is lacking and decisions for duration and dose of steroid remain largely anecdotal, however single unblinded, uncontrolled retrospective case series do show a positive role for early steroid treatment in pain reduction and shortened recovery time. ${ }^{[15]}$ The use of any long term steroids is not supported in the literature. There is no standard physical therapy regimen proven to effectively restore function and improve pain in patients with $\mathrm{NA}^{[16]}$ and long term outcomes of these treatments remain unclear. ${ }^{[3,6]}$ However, these treatment modalities have been shown to significantly improve symptoms of NA as long as treatment was started early in the disease process. ${ }^{[5]}$ Recovery with NA is variable. ${ }^{[17]}$ In one small case series $75 \%$ of patients had good recovery of muscle strength 14 months are symptom onset. ${ }^{[18]}$ Other case reports have demonstrated recovery on the order of approximately $30 \%-90 \%$ at intervals from 1 to 3 years. ${ }^{[3,19]}$

\section{Conclusion}

Neuralgic Amyotrophy is a painful disease process without a definitive pathophysiology. Diagnosis can be missed given the overlap in symptoms similar to other common musculoskeletal problems. Our patient represents a classic presentation of NA with the acute onset of pain followed by patchy weakness and sensory changes. In reality, the myriad of possible presentations and lack of definitive diagnostic testing creates confusion in making the diagnosis. Early recognition, however, is important to help relieve the pain, anxiety, and any unnecessary work up and subspecialist referrals.

\section{CONFLicts OF INTEREST Disclosure}

The authors have declared no conflicts of interest.

\section{REFERENCES}

[1] Feinberg JH, Radecki J. Parsonage-turner syndrome. HSS J Musculoskelet J Hosp Spec Surg. 2010; 6(2): 199-205. http://dx . doi . o $\mathrm{rg} / 10.1007 / \mathrm{s} 11420-010-9176-\mathrm{x}$

[2] Van Alfen N. The neuralgic amyotrophy consultation. J Neurol. 2007; 254(6): 695-704. PMid:17446996 http://dx.doi.org/10.1007 /s00415-006-0246-4

[3] Van Alfen N, van Engelen BGM. The clinical spectrum of neuralgic amyotrophy in 246 cases. Brain J Neurol. 2006; 129(Pt 2): 438-50.

[4] McGillicuddy JE. Cervical radiculopathy, entrapment neuropathy, and thoracic outlet syndrome: how to differentiate? Invited submission from the Joint Section Meeting on Disorders of the Spine and Peripheral Nerves, March 2004. J Neurosurg Spine. 2004; 1(2): 179-87. PMid:15347004 http://dx.doi.org/10.3171/spi.2004.1.2. 0179

[5] Van Alfen N, van Eijk JJJ, Ennik T, et al. Incidence of neuralgic amyotrophy (Parsonage Turner syndrome) in a primary care setting-a prospective cohort study. PloS One. 2015; 10(5): e0128361. PMid:26016482 http://dx.doi.org/10.1371/journal . pone. 0128361

[6] Squintani G, Mezzina C, Lettieri C, et al. Unusual ParsonageTurner syndrome with relapses and bilateral simultaneous anterior interosseous neuropathy. Neurol Sci Off J Ital Neurol Soc Ital Soc Clin Neurophysiol. 2009; 30(6): 513-6. http://dx . doi .org/10. 1007/s10072-009-0124-9

[7] Van Alfen N. Clinical and pathophysiological concepts of neuralgic amyotrophy. Nat Rev Neurol. 2011; 7(6): 315-22. PMid:21556032 http://dx.doi.org/10.1038/nrneurol.2011.62

[8] Genevray M, Kuchenbuch M, Kerbrat A, et al. Unusual presentation of neuralgic amyotrophy with impairment of cranial nerve
XII. Muscle Nerve. 2016; 54(2): 335-336. PMid:26788793 http: //dx.doi.org/10.1002/mus. 25031

[9] De Burca N. Brachial neuritis (Parsonnage-Turner syndrome) a case study. Man Ther. 2009; 14(5): 567-71. PMid:19211296 http://dx.doi.org/10.1016/j.math.2009.01.001

[10] Calpena E, Martínez-Rubio D, Arpa J, et al. A novel locus for a hereditary recurrent neuropathy on chromosome 21q21. Neuromuscul Disord NMD. 2014; 24(8): 660-5. PMid:24878226 http: //dx.doi.org/10.1016/j.nmd.2014.04.004

[11] Pellegrino JE, Rebbeck TR, Brown MJ, et al. Mapping of hereditary neuralgic amyotrophy (familial brachial plexus neuropathy) to distal chromosome 17q. Neurology. 1996; 46(4): 1128-32. PMid:8780104 http://dx.doi .org/10.1212/WNL .46.4.1128

[12] Van Alfen N, Hannibal MC, Chance PF, et al. Hereditary Neuralgic Amyotrophy. GeneReviews. 1993 [cited 2016 Mar 18]. Available from: http://www.ncbi.nlm.nih.gov/books/NBK1395/

[13] Scalf RE, Wenger DE, Frick MA, et al. MRI findings of 26 patients with Parsonage-Turner syndrome. AJR Am J Roentgenol. 2007; 189(1): W39-44. PMid:17579134 http://dx.doi.org/10.2214 /AJR.06.1136

[14] Gaskin CM, Helms CA. Parsonage-Turner syndrome: MR imaging findings and clinical information of 27 patients. Radiology. 2006; 240(2): 501-7. PMid:16864674 http://dx.doi.org/10.1148/r adiol.2402050405

[15] Van Alfen N, van Engelen BG, Hughes RA. Treatment for idiopathic and hereditary neuralgic amyotrophy (brachial neuritis). In: The Cochrane Collaboration, editor. Cochrane Database of Systematic Reviews [Internet]. Chichester, UK: John Wiley \& Sons, Ltd; 2009 [cited 2016 Mar 13]. Available from: http://doi . wiley . com/10 .1002/14651858. CD006976.pub2 
[16] Cup EH, Ijspeert J, Janssen RJ, et al. Residual complaints after neuralgic amyotrophy. Arch Phys Med Rehabil. 2013; 94(1): 6773. PMid:22850488 http://dx.doi.org/10.1016/j.apmr. 20 12.07 .014

[17] Tjoumakaris FP, Anakwenze OA, Kancherla V, et al. Neuralgic amyotrophy (Parsonage-Turner syndrome). J Am Acad Orthop Surg. 2012; 20(7): 443-9. PMid:22751163 http://dx.doi.org/10.54 35/JAAOS-20-07-443
[18] Monteiro Dos Santos RB, Dos Santos SM, Carneiro Leal FJC, et al. Parsonage-Turner syndrome. Rev Bras Ortop. 2015; 50(3): 33641. PMid:26229940 http://dx.doi.org/10.1016/j.rbo. 201 4.06 .007

[19] Tsairis P, Dyck PJ, Mulder DW. Natural history of brachial plexus neuropathy. Report on 99 patients. Arch Neurol. 1972; 27(2): 109-17. PMid:4339239 http://dx.doi.org/10.1001/archneur.1972 .00490140013004 